\title{
Palladium Nanoplate-based IL-6 Receptor Antagonists Ameliorate Cancer Related Anemia and Simultaneously Inhibit Cancer Progression
}

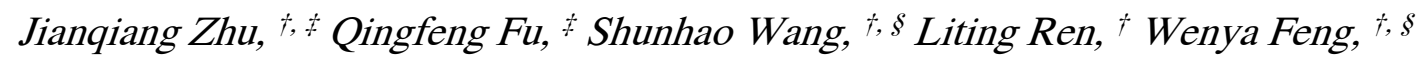
Shuting Wei, ${ }^{\star}, \xi$ Zhihong Zhang, $*$ Yong Xu, $*$ Tomas Ganz, ${ }^{\phi, * *}$ Sijin Liu, ${ }^{*}, \xi^{*}$

${ }^{\dagger}$ State Key Laboratory of Environmental Chemistry and Ecotoxicology, Research Center for Eco-Environmental Sciences, Chinese Academy of Sciences, Beijing 100085, China.

\#Department of Urology, The Second Hospital of Tianjin Medical University, Tianjin Institute of Urology, Tianjin 300211, China.

$\S$ University of Chinese Academy of Sciences, Beijing 100049, China.

q Department of Medicine, David Geffen School of Medicine, University of California, Los Angeles, CA 90095, USA.

* Corresponding authors: Sijin Liu, Ph.D. and Tomas Ganz, MD, Ph.D.

Tel: 8610-62849330; E-mail: sjliu@ rcees.ac.cn and tganz@mednet.ucla.edu.

ORCID: Sijin Liu: 0000-0002-5643-0734; Tomas Ganz: 0000-0002-2830-5469 


\section{Materials and methods}

\section{Synthesis of Palladium nanoplates (PdPLs).}

As described in recent reports, ${ }^{1-2}$ PdPLs were synthesized according to our established protocols. Briefly, $10 \mathrm{mg}$ palladium (II) acetylacetonate, $30 \mathrm{mg}$ PVP and $10 \mathrm{mg} \mathrm{Na} \mathrm{N}_{2} \mathrm{Br}$ were dissolved in $2 \mathrm{~mL}$ DMP in a glass pressure vessel, and thereafter 4 $\mathrm{mL}$ double distilled (dd) $\mathrm{H}_{2} \mathrm{O}$ was added. After being charged with $\mathrm{CO}$ to 1 bar, the vessel was heated to $60{ }^{\circ} \mathrm{C}$ from room temperature in $30 \mathrm{~min}$ in an oil bath, and was kept at this temperature for $1.5 \mathrm{~h}$ with stirring before cooling to the room temperature. Afterwards, $37.5 \mathrm{mg}$ palladium (II) acetylacetonate was added into the vessel, and was fully dissolved. And the vessel was charged with CO to 1 bar again, and was heated to $60{ }^{\circ} \mathrm{C}$ from room temperature in 60 min under an oil bath, and was kept at this temperature for $60 \mathrm{~min}$ with stirring prior to cooling to room temperature. The obtained products were successively precipitated with acetone and ethanol-acetone mixture, and were finally stored at $4{ }^{\circ} \mathrm{C}$ for future use.

\section{Surface modification of PdPLs and tocilizumab (TCZ) loading.}

Pre-synthesized PdPLs in $1 \mathrm{~mL}$ were deposited by $7 \mathrm{~mL}$ acetone to remove excrescent ions, and were thereafter subjected to the centrifugation at $8,000 \mathrm{~g}$ for $5 \mathrm{~min}$. The sediment was dissolved in $\mathrm{ddH}_{2} \mathrm{O}$, followed by the addition of mercaptopropionic acid (200 $\mu \mathrm{L}$ per $1 \mathrm{mg}$ PdPLs), and was then incubated at room temperature for $3 \mathrm{~h}$. Next, the mixture was centrifuged, and the remaining sediment was washed with $\mathrm{ddH}_{2} \mathrm{O}$ for 3 times. In the following, the sediment was re-dissolved in $3 \mathrm{~mL} \mathrm{ddH}_{2} \mathrm{O}$, followed by the addition of $75 \mu \mathrm{L}$ EDC (200 mM) and $75 \mu \mathrm{L}$ NHS $(58 \mathrm{mM})$ and subsequent 
incubation at room temperature for $1 \mathrm{~h}$. After that, $2 \mathrm{mg} \mathrm{NH}$ - $\mathrm{PEG}$ was added into the aqueous solution and incubated at room temperature for $3 \mathrm{~h}$. Then, the aqueous solution was filtered with ultrafiltration centrifuge tubes $(100 \mathrm{Kd})$, and the sediment was washed with $\mathrm{ddH}_{2} \mathrm{O}$ for 3 times. Finally, the sediment was gathered and re-dissolved in $\mathrm{ddH}_{2} \mathrm{O}$ or PBS. For TCZ loading, PdPLs solution post surface modification was mixed with TCZ (20 mg/mL) and vibrated under $4{ }^{\circ} \mathrm{C}$ overnight, and the precipitates were collected and washed 3 times after centrifugation at 15,000 rpm for $60 \mathrm{~min}$, followed by resuspension in PBS for experiments.

\section{Characterization of materials.}

The TEM samples were prepared with a carbon-coated copper electron microscopy grid (Beijing Zhongjingkeyi Technology Co., Ltd., China) and dried under room temperature. TEM analysis was performed on an H-7500 transmission electron microscope (Hitachi Scientific Instruments, Japan). For AFM determination, samples were prepared by depositing PdPLs, PdPL-PEG and PdPL-PEG@TCZ dispersion on mica substrates (Beijing Zhongjingkeyi Technology Co., Ltd., China), respectively. Then, the AFM imaging was carried out on a Dimension FastScan Bio AFM instrument in the contact mode (Bruker, Santa Barbara, California, USA) for the dried samples.

\section{Cell lines and cell culture.}

The mouse lung alveolar basal carcinoma epithelial cell line LLC, mouse macrophage cell line J774.A1, mouse breast cancer cell line 4T1, human liver cancer cell line HepG2, human kidney cancer cell line A498, and human bladder cancer cell line EJ were obtained from the Shanghai Cell Bank of Type Culture Collection of China. 
Cells were conventionally cultured in Dulbecco's modified Eagle's medium (DMEM)

(Gibco BRL Life Technologies Inc., USA) supplemented with 10\% bovine serum (Gibco BRL Life Technologies Inc., USA), and $1 \%$ penicillin/streptomycin (Hyclone, CA, USA) in the presence of $5 \% \mathrm{CO}_{2}$ at $37{ }^{\circ} \mathrm{C}$, as previously described in our laboratory. ${ }^{3}$

\section{Animal experimentation and cancer cell implantation.}

All animal experiments were carried out in accordance with the guidelines approved by the Animal Ethics Committee at the Research Center for EcoEnvironmental Sciences, Chinese Academy of Sciences. In this study, male C57BL/6 and BALB/c mice ( $\sim 20$ g body weight, $\sim 8$ weeks old) were purchased from the Vital River laboratories (Beijing, China). The cancer-related anemia (CRA) mouse model was established through LLC cancer cell implantation via intraperitoneal injection of 3 $\times 10^{6}$ cells for each C57BL/6 mouse, as previously described. ${ }^{4}$ The AI mouse model was established through the induction of heat-killed Brucella abortus (BA) cells, as previously documented. ${ }^{5}$ The mouse model of breast cancer was established through 4T1 cells orthotopic injection at the left fourth mammary fat pads (MFPs), and each mouse was administrated $1 \times 10^{6}$ cells, as previously described. ${ }^{6}$

\section{Complete blood count (CBC) assay.}

For $\mathrm{CBC}$ analysis, $20 \mu \mathrm{L}$ fresh blood was collected from mice and immediately diluted in $2 \mathrm{~mL}$ diluent buffer. $\mathrm{CBC}$ parameters including white blood cell (WBC), red blood cell (RBC) and the hemoglobin (HGB) content were measured on a MEK-7222K automated hematology analyzer (Nihon Kohden, Japan). 


\section{Blood biochemistry assays.}

The concentrations of serum iron were determined with a kit from the Nanjing Jiancheng Bioengineering Institute, China. The concentrations of IL-6 in sera were quantitatively measured with an IL-6 Enzyme-Linked Immunosorbent Assay (ELISA) kit (R\&D Systems Technologies, USA).

\section{Cellular viability assay.}

To assess cell growth, cells were seeded in 96-well plates with a density of $1 \times 10^{4}$ cells/ well. After different treatments, cell viability was determined by the cell counting kit-8 analysis (CCK8, Solarbio Science \& Technology Co., Ltd., Beijing, China).

\section{Western blot analysis.}

Post treatments, cells were collected and washed with cold PBS for 3 times, and collected cells were then lysed in the RIPA lysis buffer (Pierce Lysis Buffer, USA) supplemented with $10 \%$ protease inhibitor cocktail (Roche, Switzerland) and 1\% phosphatase inhibitor (Solarbio Science \& Technology Co., Ltd., Beijing, China). Mouse liver tissues were homogenized for total protein extraction using a SCIENTZ48 tissue lyser kit (Ningbo Scientz Biotech Co Ltd., China). Protein concentrations were assayed with the BCA method (Solarbio Science \& Technology Co., Ltd., Beijing, China). Equal amounts of proteins were subjected to sodium dodecyl sulfate polyacrylamide gel electrophoresis (SDS-PAGE) separation, followed by transfer to nitrocellulose membranes for blotting, as described previously. ${ }^{7}$ The primary antibodies (Abs) included the anti-P-STAT3 (Tyr705) Ab (1:1000 dilutions, Cell Signaling Technology, USA) and anti- $\beta$-actin Ab (Proteintech, China). 


\section{Luciferase assays.}

HepG2 cells were seeded in a 24-well plate and co-transfected with $0.2 \mu \mathrm{g}$ of hepcidin (HEPC) luciferase reporter construct (as established in our laboratory ${ }^{8}$ ) and $0.05 \mu \mathrm{g}$ of renilla luciferase plasmid by Lipofectamine 2000 (Invitrogen, USA). At $4 \mathrm{~h}$ post-incubation, cells were replaced with fresh medium, and $48 \mathrm{~h}$ later, cells were pretreated with TCZ (at $5 \mu \mathrm{g} / \mathrm{mL}$ ) for $2 \mathrm{~h}$, followed by the challenge of $10 \mathrm{ng} / \mathrm{mL}$ IL-6. Thereafter, cells were cultured for another $6 \mathrm{~h}$, and then the dual-luciferase reporter assay (Promega, USA) was performed, as described. ${ }^{9}$ At last, the luciferase activity of HEPC luciferase reporter construct was normalized to that of renilla luciferase.

\section{Coomassie blue staining.}

After the running of SDS-PAGE, the gel was peeled off from the glass plates, followed by fast staining using the Coomassie Brilliant Blue Fast Staining solution following the standard protocol from the manufacturer (Solarbio, Beijing, China). Finally, the stained protein bands in gels were visualized and imaged under a Bio455 Rad ChemiDoc XRS system (Bio-Rad Inc., CA, USA).

\section{Biodistribution of PdPLs in mice.}

To look into the distribution profiles of PdPLs, mice were intravenously injected with PdPL-PEG nanomaterials at $5 \mathrm{mg} / \mathrm{Kg}$ body weight. Afterwards, mice were sacrificed at $1,3,12$ and $72 \mathrm{~h}$ post intravenous injection ( $\mathrm{n}=5$ for each time point). Various organs were collected and weighed, followed by lysis in $\mathrm{HNO}_{3}$ and $\mathrm{H}_{2} \mathrm{O}_{2}$ mixture solution, as described previously. ${ }^{7}$ The Pd mass was measured by ICP-MS method on an ICP-MS instrument (Agilent 8800, Japan), and the percentage of injected 
dose per gram of organ was accordingly calculated, namely $\% \mathrm{ID} / \mathrm{g}$, as described. ${ }^{3}$

\section{In vivo tumor bio-luminescent imaging.}

Three weeks post implantation of LLC cells (which bear the luciferase reporter system) in abdominal cavity, mice were given an intraperitoneal injection of the substrate, luciferin (Promega, Fitchburg, WI, USA) at a dose of $100 \mathrm{mg} / \mathrm{Kg}$ body weight. Mice were anaesthetized by isoflurane, and the luciferase bio-luminance was imaged using an IVIS® Lumina II Imaging System (Caliper Life Sciences, Hopkinton, MA).

\section{Histological examination.}

For histological examination, diverse organs were immediately dissected from mice and were quickly fixed in $10 \%$ PBS-buffered formalin. Tissues were regularly embedded with paraffin, and were then sliced into 5- $\mu$ m thick sections. Following the standard protocols as documented, ${ }^{10} \mathrm{H} \& \mathrm{E}$ blue staining was afterwards performed. Slides were imaged on an Axio Scope A1 optical microscope (Carl Zeiss, Inc., Germany), as previously described. ${ }^{11}$

\section{L-6 treatment.}

Human IL-6 (hIL-6) recombinant protein was purchased from the Peprotech, Inc. (Rocky Hill, NJ, USA). The doses used in vitro and in vivo here were referred to a justified wide range in signaling studies, as descried previously. ${ }^{12,13}$ The control group received PBS only.

\section{Statistical analysis.}

All experimental data are shown as the mean \pm standard deviation (SD). Statistical analyses were implemented using the Student's t-test between every 2 groups, and one- 
way ANOVA test was applied among $\geq 3$ groups. Here, $\mathrm{P}<0.05$ was determined as statistically significant difference. 


\section{Supplementary results}
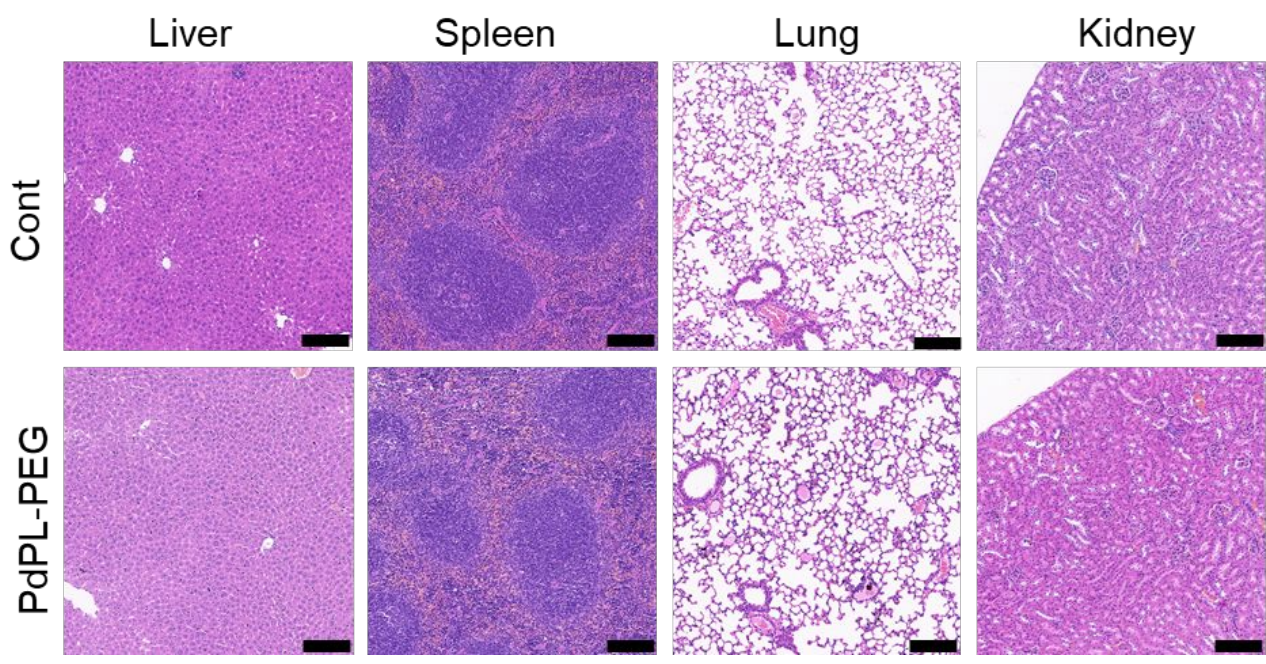

Figure S1. Histological examination of tissues from mice upon PdPL-PEG for 7 days.

Representative images of H\&E staining of liver, spleen, lung and kidney (scale, 100 $\mu \mathrm{m})$. 
(a)

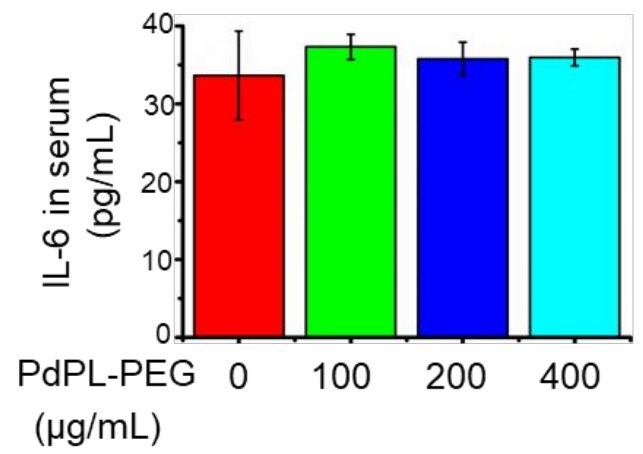

(b)

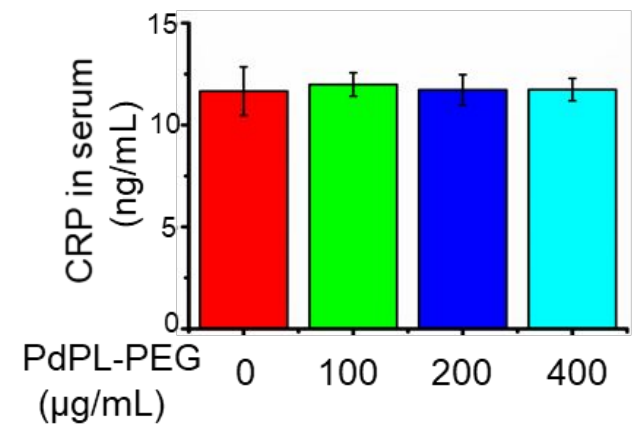

Figure S2. Assessment of inflammation in mice in response to PdPL-PEG. Mice were administrated with $100 \mu \mathrm{L}$ PdPL-PEG nanomaterials through intravenous injection at 3 different doses $(100,200$ and $400 \mu \mathrm{g} / \mathrm{mL})$ for $24 \mathrm{~h}$. The serum concentrations of serum IL-6 (a) and c-reaction protein (CRP) (b) were then assayed $(n=5)$. 
(a)

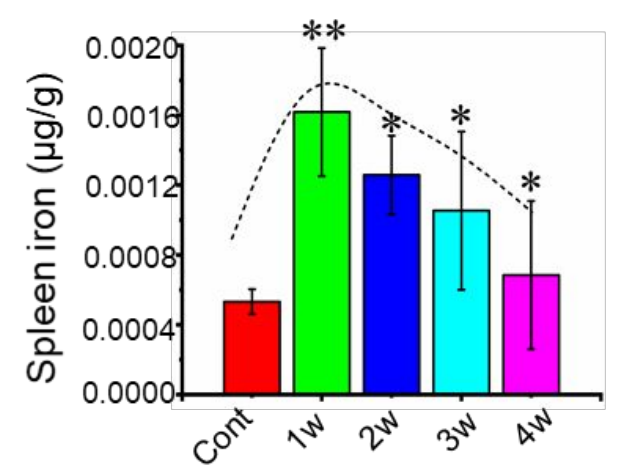

(b)

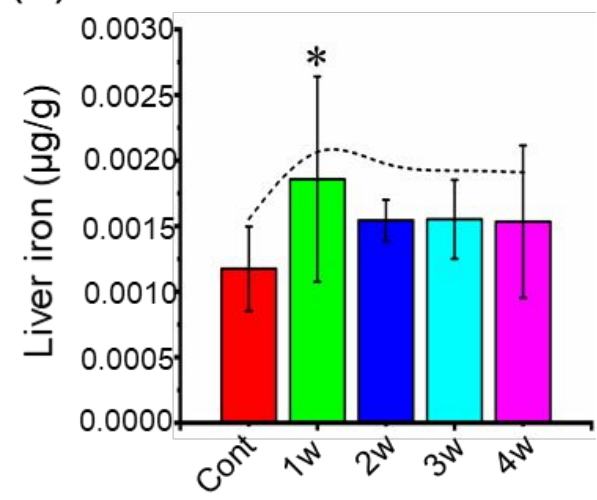

Figure S3. Tissue iron content in mice post intraperitoneal implantation of LLC cells.

At different time points after intraperitoneal implantation of LLC cells, (a) splenic and

(b) hepatic iron mass was determined. *: $\mathrm{P}<0.05, * *$ : $\mathrm{P}<0.001$ compared to the untreated control $(\mathrm{n}=5)$. 


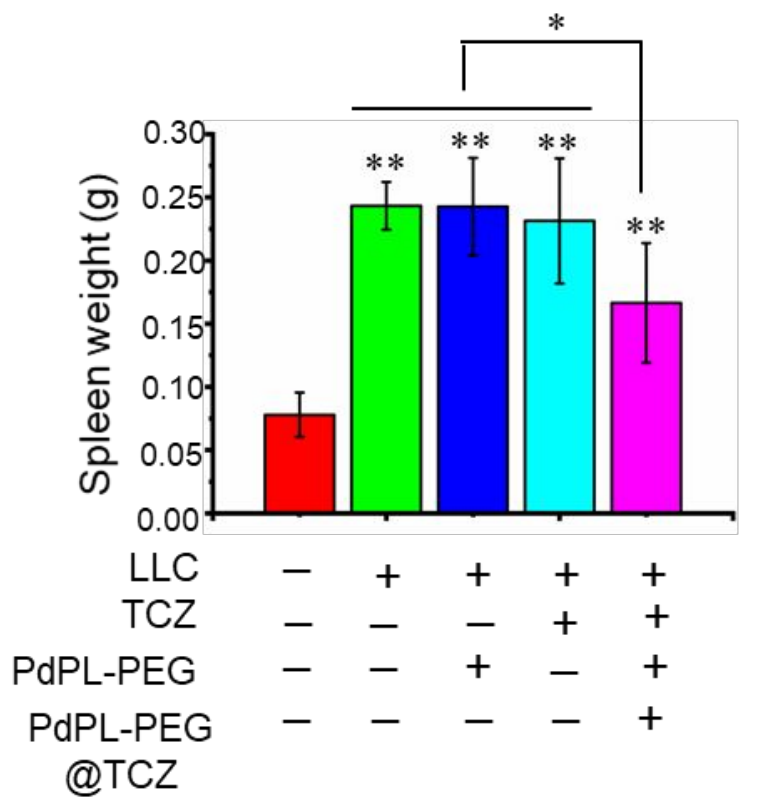

Figure S4. Spleen weight changes in mice receiving LLC cell implantation with or without treatments. *: $\mathrm{P}<0.05 ; * *: \mathrm{P}<0.001$, relative to the control group or between indicated groups $(\mathrm{n}=5)$. 

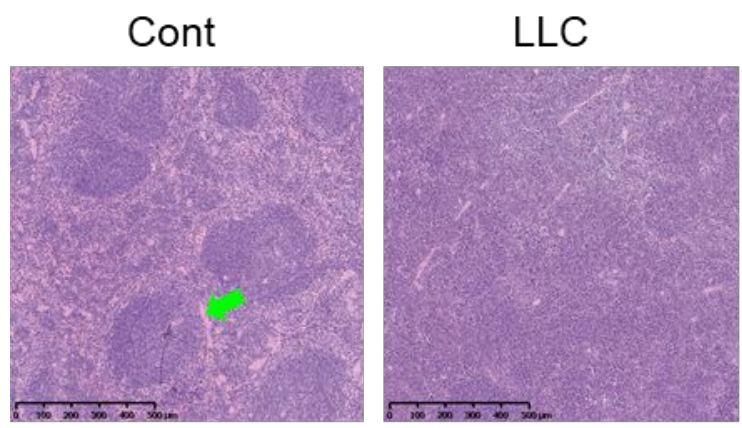

LLC/PdPL-PEG
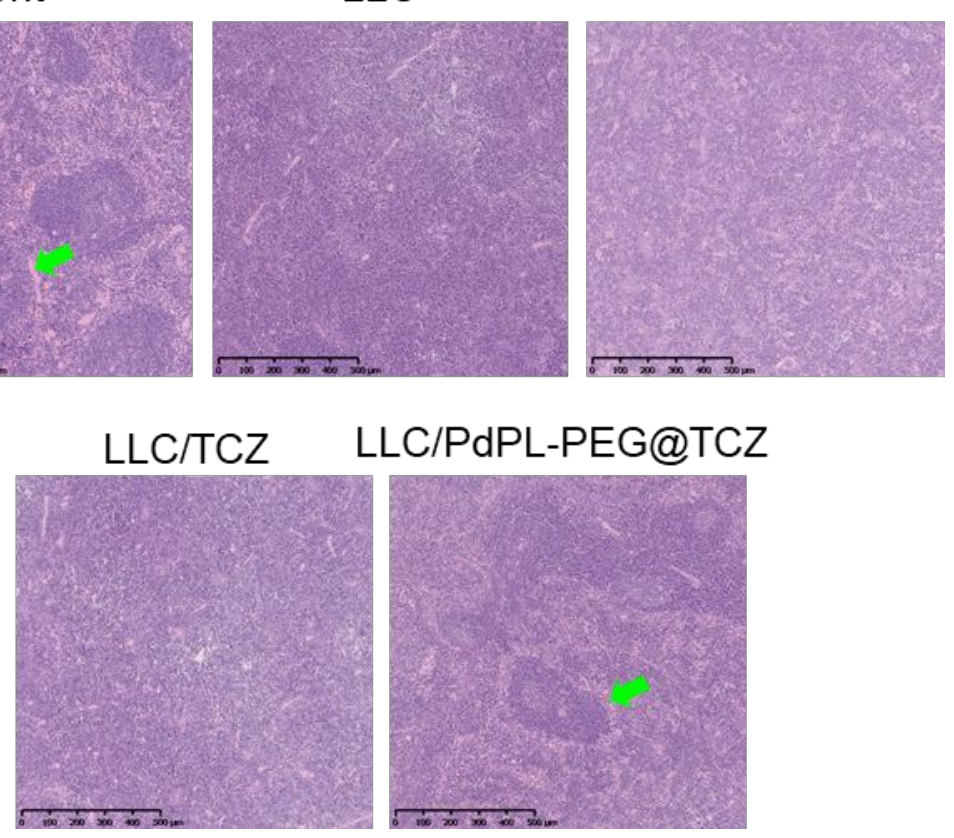

Figure S5. Histological examination of tissues from mice with LLC cell implantation post different treatments. The green arrows show the normal boundary between the white pulp and red pulp in the spleen. 
(a)

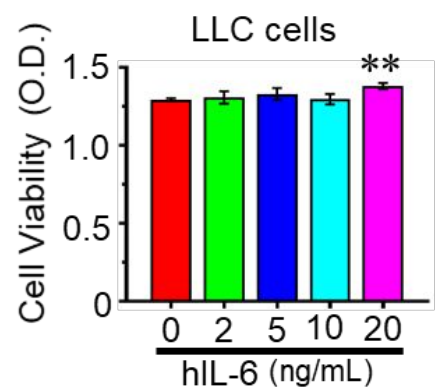

(c)

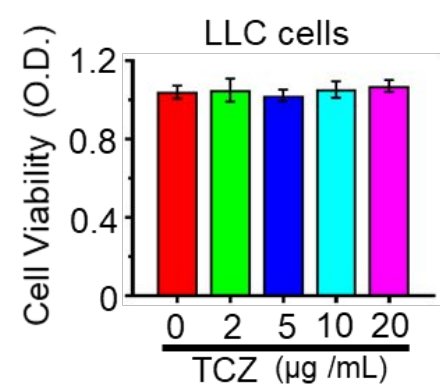

(e)

(g)
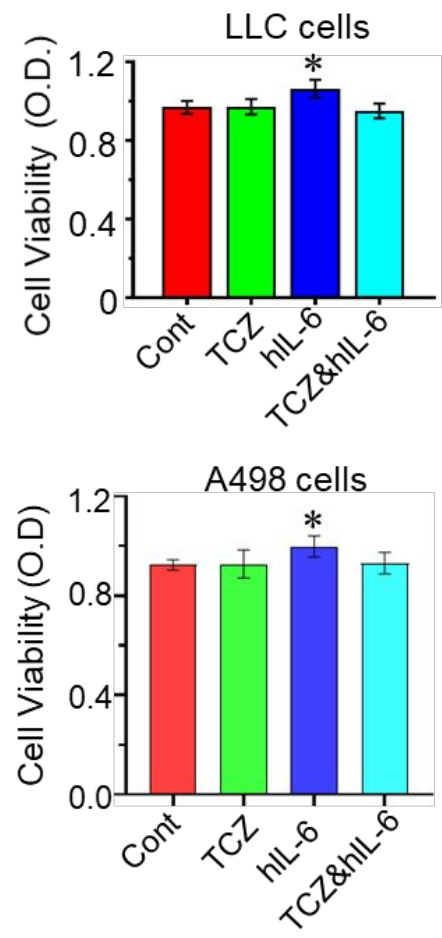

(b)

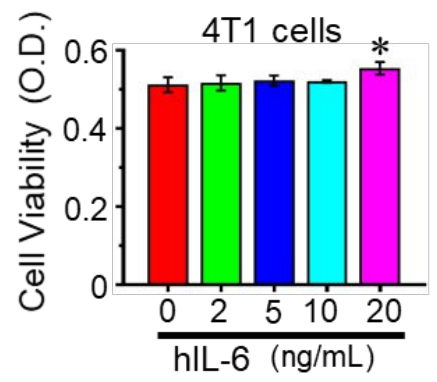

(d)

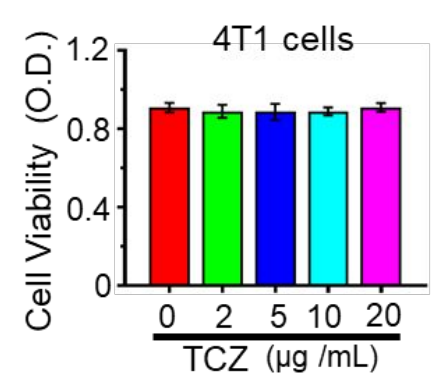

(f)

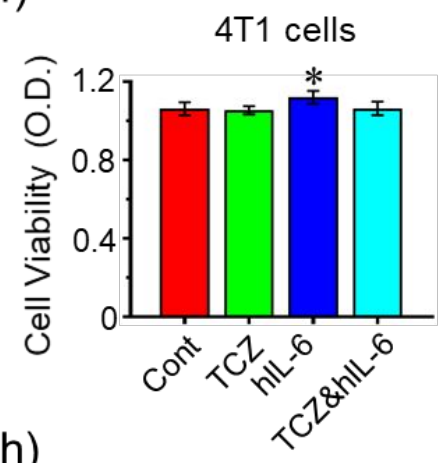

(h)

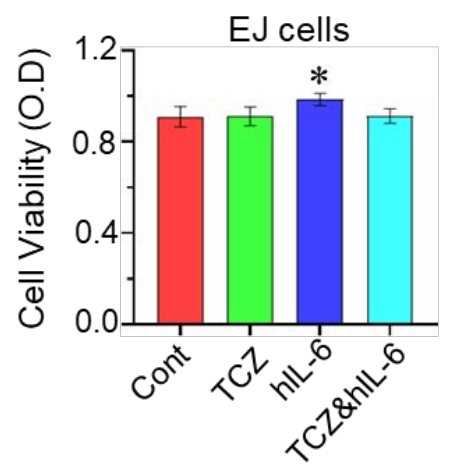

Figure S6. The inhibiting effect of TCZ on IL-6-stimulated proliferation in various cancer cell lines. (a-b) hIL-6 slightly promotes LLC and 4T1 cell proliferation at 20 $\mathrm{ng} / \mathrm{mL}$ for $24 \mathrm{~h}$. (c-d) TCZ treatment has no effect on the proliferation of LLC and 4T1 cells. (e-h) TCZ pre-treatment for $2 \mathrm{~h}$ at $2 \mu \mathrm{g} / \mathrm{mL}$ compromises the promoting effect of 
hIL-6 (at $20 \mathrm{ng} / \mathrm{mL}$ ) on the proliferation of LLC, 4T1, A498 and EJ cells for $24 \mathrm{~h}$. *: P $<0.05$, compared to the control group $(n=6)$. 
(a)

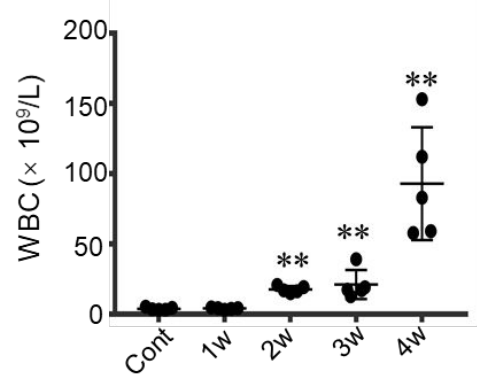

(c)

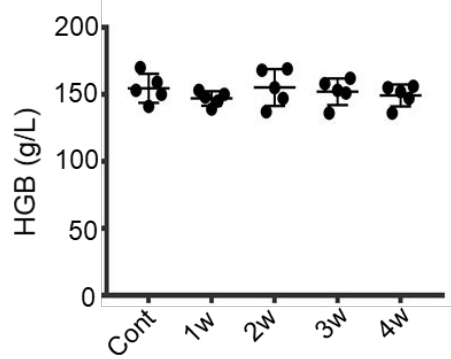

(b)

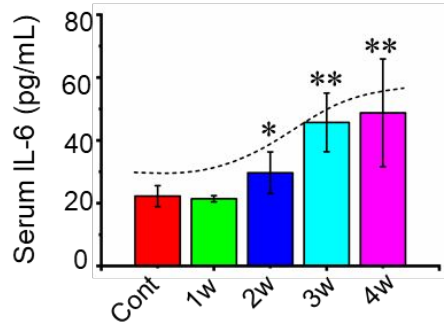

(d)

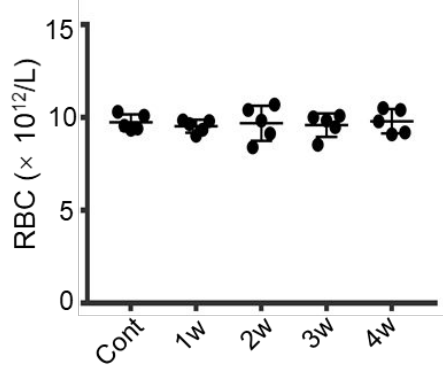

Figure S7. Establishment of the cancer model with inflammation but without anemia through orthotopic injection of 4T1 cells. (a-b) WBC count and serum IL-6 content in mice with orthotopic transplantation of 4T1 cancer cells over time. (c-d) RBC and HGB content in these mice. *: $\mathrm{P}<0.05, * *: \mathrm{P}<0.001$, compared to the control group $(\mathrm{n}=5)$. 
(a)

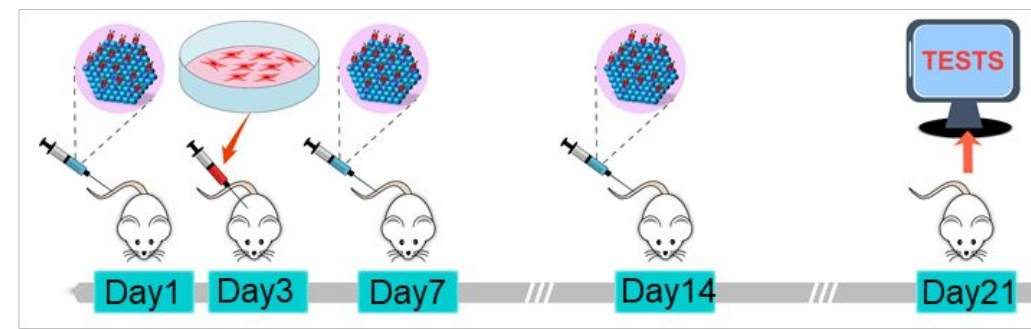

(b)

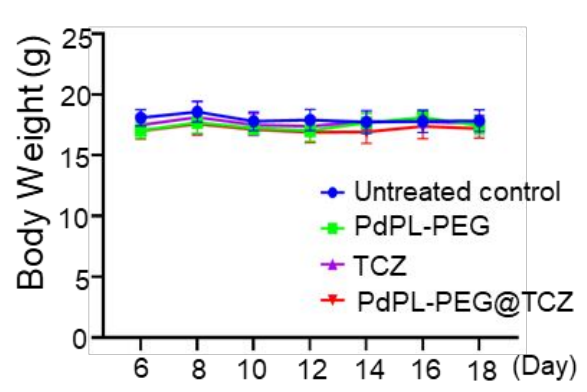

(d)

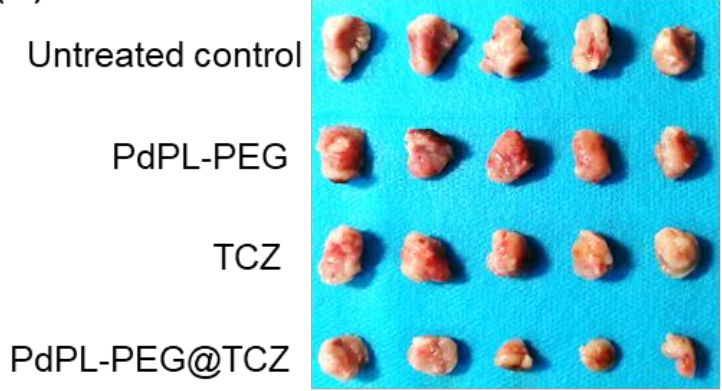

$\rightarrow$ Untreated control

(c) $\stackrel{\text { ก }}{\text { ह }} 12007 \rightarrow$ PdPL-PEG

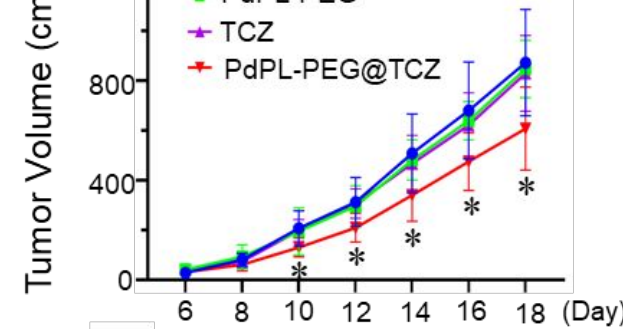

(e)

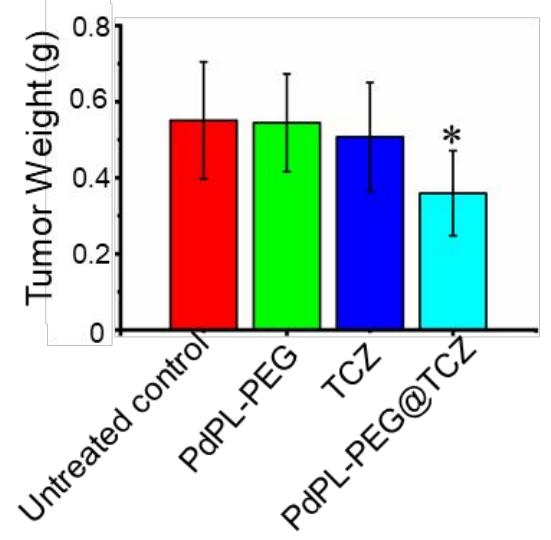

Figure S8. The therapeutic effect of PdPL-PEG@TCZ in 4T1 tumor mouse model. (a)

A schematic diagram delineating the experimental design, where the dose of TCZ was at $5 \mathrm{mg} / \mathrm{Kg}$ body weight and PdPL-PEG@TCZ carried the same mass of TCZ relative to the free TCZ control group. (b) Body weight changes and (c) tumor volume was monitored over time, and (d) tumor images and (e) tumor weight were determined at the end of experiments. *: $\mathrm{P}<0.05$, compared to the control group $(\mathrm{n}=5)$. 


\section{REFERENCES}

(1) Chen, X. L.; Li, J. C.; Huang, Y. Z.; Wei, J. P.; Sun, D.; Zheng, N. F. The biodistribution, excretion and potential toxicity of different-sized Pd nanosheets in mice following oral and intraperitoneal administration. Biomater Sci-Uk 2017, 5(12), 24482455.

(2) Huang, X. Q.; Tang, S. H.; Mu, X. L.; Dai, Y.; Chen, G. X.; Zhou, Z. Y.; Ruan, F. X.; Yang, Z. L.; Zheng, N. F. Freestanding palladium nanosheets with plasmonic and catalytic properties. Nat Nanotechnol 2011, 6(1), 28-32.

(3)Zhu, J. Q.; Xu, M.; Gao, M.; Zhang, Z. H.; Xu, Y.; Xia, T.; Liu, S. J. Graphene

Oxide Induced Perturbation to Plasma Membrane and Cytoskeletal Meshwork Sensitize Cancer Cells to Chemotherapeutic Agents. Acs Nano 2017, 11 (3), 2637-2651. (4)Kim, A.; Rivera, S.; Shprung, D.; Limbrick, D.; Gabayan, V.; Nemeth, E.; Ganz, T. Mouse models of anemia of cancer. Plos One 2014, 9 (3), e93283.

(5)Kim, A.; Fung, E.; Parikh, S. G.; Valore, E. V.; Gabayan, V.; Nemeth, E.; Ganz, T. A mouse model of anemia of inflammation: complex pathogenesis with partial dependence on hepcidin. Blood 2014, $123(8), 1129-1136$.

(6) Yin, C. Y.; Wang, S. H.; Ren, Q. Z.; Shen, X. M.; Chen, X. D.; Liu, Y. J.; Liu, S. J. Radial extracorporeal shock wave promotes the enhanced permeability and retention effect to reinforce cancer nanothermotherapeutics. Sci Bull 2019, 64 (10), 679-689.

(7)Zhu, J. Q.; Xu, M.; Wang, F. F.; Gao, M.; Zhang, Z. H.; Xu, Y.; Chen, W.; Liu, S. J. Low-dose exposure to graphene oxide significantly increases the metal toxicity to macrophages by altering their cellular priming state. Nano Res 2018, 11 (8), 4111-4122. 
(8)Hou, Y. L.; Zhang, S. P.; Wang, L.; Li, J. P.; Qu, G. B.; He, J. Y.; Rong, H. Q.; Ji, H.; Liu, S. J. Estrogen regulates iron homeostasis through governing hepatic hepcidin expression via an estrogen response element. Gene 2012, 511 (2), 398-403.

(9)Liu, J.; Liu, W.; Liu, Y.; Miao, Y.; Guo, Y.; Song, H.; Wang, F.; Zhou, H.; Ganz, T.; Yan, B.; Liu, S. New thiazolidinones reduce iron overload in mouse models of hereditary hemochromatosis and beta-thalassemia. Haematologica 2019, 104 (9), 17681781.

(10) Yang, Y.; Wu, Y. K.; Ren, Q. Z.; Zhang, L. G.; Liu, S. J.; Zuo, Y. Y. Biophysical Assessment of Pulmonary Surfactant Predicts the Lung Toxicity of Nanomaterials. Small Methods 2018, 2(4).

(11) Gao, J.; Sanchez-Purra, M.; Huang, H.; Wang, S. H.; Chen, Y. N.; Yu, X. F.; Luo, Q.; Hamad-Schifferli, K.; Liu, S. J. Synthesis of different-sized gold nanostars for Raman bioimaging and photothermal therapy in cancer nanotheranostics. Sci China Chem 2017, 60(9), 1219-1229.

(12) Lin, C.; Liao, W.; Jian, Y.; Peng, Y.; Zhang, X.; Ye, L.; Cui, Y.; Wang, B.; Wu, X.; Xiong, Z.; Wu, S.; Li, J.; Wang, X.; Song, L. CGI-99 promotes breast cancer metastasis via autocrine interleukin-6 signaling. Oncogene. 2017, 36(26), 3695-3705. (13) Gavito, A.L.; Cabello, R.; Suarez, J.; Serrano, A.; Pavón F.J.; Vida, M.; Romero, M.; Pardo, V.; Bautista, D.; Arrabal, S.; Decara, J.; Cuesta, A.L.; Valverde, A.M.; Rodríguez de Fonseca, F.; Baixeras, E. Single administration of recombinant IL-6 restores the gene expression of lipogenic enzymes in liver of fasting IL-6-deficient mice. Br J Pharmacol. 2016, 173(6), 1070-84. 